\title{
Incidence of internal marketing and organizational commitment in the retail sector
}

\author{
Junior Canales-Requena ${ }^{a}$, Olenka Ccanto-Inga ${ }^{a}$, Johann Mendizabal Lizarbe ${ }^{a}$ and Wagner Vicente- \\ $\operatorname{Ramos}^{\mathrm{a}^{*}}$
}

${ }^{a}$ Universidad Continental

\section{H R O N I C L E}

Article history:

Received March 8, 2021

Received in revised format May 5 , 2021

Accepted June 152021

Available online

July 252021

Keywords:

Internal marketing

Organizational commitment

Affective commitment

Permanence commitment

Normative commitment

\begin{abstract}
A B S T R A C T
The objective of this study was to determine the impact of internal marketing on the organizational commitment of employees in the retail sector. The method used was a quantitative correlational approach, at an explanatory level with a non-experimental design. The study sample consisted of 392 workers belonging to the retail sector. The results generated by structural equations show that specific relationships have $\mathrm{p}<0.05$, i.e. all the proposed hypotheses are accepted in the proposed correlation between internal marketing and the three types of organizational commitment, among them the affective commitment, which generates emotional ties between the employee and the organization, feeling proud to remain in the same linking the values and objectives of the same as their own goals, the commitment of permanence, which implies the risks involved in separating from the organization as well as the loss of all the benefits obtained and how these would be difficult to obtain if the employee were to leave the organization. Finally, the normative commitment, which arises when the employee perceives some kind of opportunity or special benefit in the organization, thus generating a bond of moral reciprocity, i.e. a bond of loyalty. The conclusion of the study is that the use of internal marketing for personnel selection is a fundamental tool for achieving acceptable levels of the three types of commitment mentioned above. This ensures the efficiency of the company both internally and externally, with long-term results.
\end{abstract}

\section{Introduction}

Nowadays, many organizations face the challenge of finding in their collaborators the loyalty and commitment necessary for both economic and cultural achievement within the organization, due to the current reality that has caused a rotational flow of personnel due to various circumstances that make up the work environment, including procedures, standards, regulations, work organization, working hours, schedules, salaries, personal development opportunities, job security, among many others, and organizations seek to determine the necessary tools to mitigate these requirements on the part of the personnel. According to Edel et al. (2007), knowledge is not enough to solve problems and achieve the goals and objectives of an organization; a series of attitudes, skills and abilities are also necessary. The attitude of commitment is considered one of the most important attitudes for the achievement of the common objective; it is the intensity of a collaborator's participation and identification with the organization, which is characterized by; the acceptance and belief in the goals and values of the organization, the willingness to make an important effort for the benefit of the organization and finally the desire to belong to the organization. According to Rafiq and Ahmed (2000) internal marketing was first proposed as a solution to the problem of delivering consistently high quality service. However, although the concept has evolved over the last twenty years, very few companies globally are implementing the concept in practice. The importance with which internal marketing is recognized is based on the fact that employees, regardless of their position within the organization, will exert a vital influence on the value that the

* Corresponding author

E-mail address: wvicente@ continental.edu.pe (W. Vicente-Ramos)

(c) 2021 Growing Science Ltd. All rights reserved.

doi: $10.5267 /$ j.uscm.2021.7.009 
organization seeks to provide to its external customers. Therefore, if we analyze the need for organizations to create value for customers in the long term and at the same time maintain a personalized and direct relationship with them, we can understand the important role that employees play in the success of organizations. According to Chiavenato (2006), over the years new approaches to management have emerged, which proposes a classification of the various management theories, the most prominent of which is the scientific management theory. Theories such as bureaucratic, structuralist and neoclassical highlight the classical structure of management and arise in contrast theories such as the theory of human relations, organizational behavior and people-centered organizational development. Those that emphasize the environment as structuralist and contingency theories. It should be taken into account that in organizations conflicts between individual objectives and organizational objectives are very common. Therefore, theories such as those of human relations based on the behavior of the individual can reconcile this type of conflict, without losing sight of the harmony of an ideal work environment for the organization. according to Hernández et al. (2018) regarding commitment, the employee must be aware of his work environment, willingness to maintain lines of activity, satisfaction with bonuses, salaries and perceived promotions. All of the above influences the motivation that the organization generates in its collaborators. The organization will achieve its objectives, promoting communication and teamwork, which in turn allows to recognize the leader within the organization.

From a global point of view, the commitment of employees represents a primary indicator in any organization, given that a higher degree of identification on the part of employees towards the organization positively influences the performance of their functions, ensuring an increase in productivity and consequently improving the profitability of the same Hewitt (2017). In Latin America the level of organizational commitment reached a rate of $72 \%$, being higher than the $59 \%$ represented by markets in the United States, Asia and Europe. It was reported that Latin America has generally shown a higher rate compared to other regions of the world, and that this trend is attributed to the fact that most Latin Americans value the factors involving engagement less critically. The factors that drive engagement levels are management leadership in organizations, professional development training opportunities, perceived recognition within organizations, and perceived compensation. It should be noted that employee commitment is defined as the degree of psychological investment on the part of the collaborator towards their organization, and that at the same time they understand what and which are the responsibilities of each collaborator within the organization, thus creating a culture of long-term commitment Albinez Loayza and Gallardo Montoya (2020). It also details that in the current labor market, companies are managing talent to three generation baby boomers, generation $\mathrm{Y}$, and generation $\mathrm{Y}$, each with different characteristics and talents, where each generation is directed and motivated from different priorities, personalized strategies and focused on aspects that commit them more and more with the organization.

In Peru, $87 \%$ of Human Resources leaders indicate that the lack of commitment in organizations is a problem that many organizations are experiencing. Sixty percent of them determine the lack of an established program for the identification of commitment levels and only $12 \%$ claim to have created a program to be able to determine the degree of commitment of collaborators, only 7\% consider themselves highly trained to promote, measure and improve commitment within the organization and thus avoid possible rotations. In recent years many Peruvian companies are working to increase the level of commitment of their collaborators and are not only based on the identification of dimensions that generate them but also on executing actions in those dimensions that drive continuous commitment, which is why the commitment index has been increasing in Peru reaching the first place with a rate of $74 \%$ in terms of commitment to their organizations, surpassing the overall average (Hewitt, 2017).

\section{Literature review}

\subsection{Internal Marketing}

Internal marketing is presented as a means to value the employee in order to motivate him and transform him into an essential resource for the company, a place where his ideas are taken into account and where he can develop his full potential with the objective of increasing productivity in any organization. According to Broady-Preston (2002), the concept of internal marketing first appeared in the literature no more than 20 years ago, Berry E. being one of the first to define it; however, to date there is no single theoretical definition of the term, since the concept has evolved over the years. Rafiq and Ahmed (1993) present a division of internal marketing into three stages; employee motivation and satisfaction, consumer orientation, and strategy implementation and management change. Employee motivation is a principle focused on employee motivation and satisfaction with the objective of improving service quality. The employee is seen as a customer, and his work as the product that sells to the organization. Consumer orientation is a principle that seeks to share with employees a market mentality and influence in the development of external customer satisfaction. It is in this way that internal marketing is applied as a means of integrating the various functional areas and is vital to the customer's relationship with the organization. Finally, the implementation of strategies is a strategic approach to reduce potential conflicts between departments, groups, committees and others in order to eliminate resistance to change within organizations.

\subsubsection{Approaches to the Internal Marketing process}

Considering that the processes are steps in an orderly manner which obey systemic behaviors, this orientation is included, which tries to explain internal marketing as the base relationship of marketing, that is, where there is a supply and a demand. This concept considers that all sectors of an organization are simultaneously suppliers and customers, starting with the 
marketing area itself which identifies the needs of customers to the sector of guaranteed services which solve the problems of the product or service delivered, this is a perspective with origin in the Totality quality management founded by Deming (1989) method of quality whose main objective is that the employees of an organization take and ensure awareness of each of the areas of the organization.

\subsubsection{Internal Marketing Dimensions}

The durability of an organization over time is determined by its ability to innovate and create lasting value, for Ospina (2019) this is based on generating credibility about the organization and at the same time over passing the expectations that internal customers have of it, integrating suggestions and ideas in favor of the organization, this is how we must begin to work the concepts of internal marketing within any organization and thus strengthen ties with our employees through different lines of access, perceived by each of our internal customers. The model designed by Bohnenberger (2006) on the dimensions of internal marketing involves four essential dimensions; personnel development, employee recruitment, job suitability and internal communication, all of them necessary tools to consolidate and guarantee productivity within the organization.

\section{Internal Communication}

The management of internal communication is focused on the actions and methods applied where those in charge of communication plan all possible resources that allow a better development in the organization, most authors agree that when an internal customer is well informed continuously, convinced of the information he receives, that he knows the objectives of the organization, the benefits or services offered by the same, even more if he is recognized and is able to freely express his ideas this is manifested in a positive attitude towards the organization. Bohnenberger (2006) states that the marketing area has several communication tools and knows how to achieve good results and it depends on the organization itself that it can have support from third parties, for example, a company that offers the creation of communication tools, In the same way it is reflected in the image of the organization since the collaborator is the main critic and if he feels at ease he will show it in his environment generating a very good image of the organization and all this is given starting from the organizational culture, for this reason it is important the information that is transmitted since a well transmitted information will have as results more effective employees at the time of doing their work.

Job suitability

The dimension of adaptation to the job is based on the actions taken by the organization to determine the motivations and skills of each employee and focus them on the functions to be performed within the organization and thus be more familiar with their position and with the objectives of the organization Zegarra Del Rosario (2014). One of the biggest problems for a company is the adaptation of the employee in the same, for this reason the human resources area works a lot on this point especially in the recognitions that are considered management tools that strengthen the relationship organization - employee, both kinds of recognition motivate the employee to commit to the culture and general objectives of the company, although it is true that the responsibility for the execution of the group of actions inferred in terms of personnel recruitment is the essential responsibility of the human resources area, in this dimension the marketing area can also contribute with suggestions for the execution of actions related to informal recognition (Bohnenberger, 2006).

\section{Recruitment of internal customers}

This dimension is considered as the recruitment and selection of personnel, however, in this study we make the repeated connotation of considering them with the term of internal customers, collaborators or simply people, beyond being titled as workers or collaborators of a company (Bohnenberger, 2006). For this, the processes of recruitment, selection, hiring and induction of human talent must be dedicated and effective, as a holistic whole these are part of the process of integrating staff to the organization, this awareness is even more important when the organization is part of the service sector, where the interaction with the customer is direct and constant, on the other hand a well done recruitment will have positive results for the internal customer who will be more than satisfied with their work.

\section{Personal development}

For Bohnenberger (2006), personnel development refers to the development of a culture of knowledge of the client, the training of the collaborators serves so that they know what should be done and mainly why it should be done. This will allow to create a greater personal interest and a greater motivation in the collaborators for wanting to develop their work optimally, to know better their external client and their needs and consequently to give a better service. Lings (2004) the concern is not in learning how to perform the activity, but in combining various factors that the employee has the possibility to develop in an integrated manner, in the different activities of the company through improvements in the performance of daily tasks through systems and methodologies to perform the work. The trainings, workshops and resources related to the employee's training contribute to perform in a more efficient way their functions, to have a wide knowledge, to develop as a person and professional within the organization.

\subsubsection{Benefits of using internal marketing}


From a human resources point of view, according to Hunt and Morgan (1995), the benefits of internal marketing in small and medium-sized companies can be seen as an intangible resource with the following attributes: it is capable of providing a competitive advantage, since it is scarce and many companies are still unaware of its benefits; it allows this competitive advantage to be sustainable over time, since the effects it provides take time to fade; finally, it is difficult to imitate by competitors, since this attribute is not easy to transfer between companies, it is not possible to buy it and it is often difficult to copy it.

\subsection{Organizational Commitment}

Organizational commitment is the degree to which an employee identifies with a particular organization, with its values, goals, vision, mission and wishes to remain in it as one of its members Uribe Prado et al. (2015) organizational commitment refers to the loyalty or bond of the individual to the organization that employs him, the commitment of people is ideally directed to think about complex problems, to establish a process of participation of individual attitudes and knowledge, projected towards an innovative action which modifies and improves the organization in all aspects, ensuring the systemic development of the individual. Slocum and Hellriegel (2009) consider that organizational commitment goes far beyond loyalty and includes an active contribution to the achievement of an organization's objectives and likewise represents a broader attitude towards work than job satisfaction, since it applies to the whole organization and not only to the job, but moreover commitment is also generally much more stable than satisfaction since it is less likely that some daily event could change it.

\subsubsection{Dimensions of Organizational Commitment}

According to Meyer and Allen (1991), they proposed a division of commitment into three components, which are considered as dimensions of the second variable of the research in question. It should be emphasized that this model has been chosen since there is a greater amount of knowledge and studies that refer to it. Taking into account that these are different in terms of their causes and consequences; affective commitment, continuity or coexistence commitment and finally normative commitment.

\section{Affective commitment}

Commitment is an essential variable to understand work behavior basically in the attitude of the individual towards the organization, affective commitment by its characteristics stands out as a desirable factor in organizations, this type of commitment is developed when the collaborator based on his experience within the company covers his expectations and at the same time satisfies his basic needs, likewise when people feel appreciated and treated as family, they will be more committed to the organization and therefore improving their performance (Guaderrama, 2016). It is also based on the person's desire to belong to an organization, it is related to feelings of belonging, affection and joy, i.e. the formation of emotional ties that bind the individual to the organization. Meyer and Allen (1991) determined that the process of forming emotional ties involves the evaluation made by employees of the support and benefits received from the organization in satisfying needs. If evaluations evolve positively, employees will begin to perceive the organization's objectives as if they were their own and will want to continue belonging to the organization because they will consider it part of their lives.

\section{Commitment to continuity}

Continuity commitment can be defined as the difficulty felt by the employee to change his relationship with an organization because the alternative offer is limited or because of the cost involved in the change (Arango, 2016). The continuity commitment by means of two events that restrict the collaborator from making a change from that organization to another offeror, each of these events act independently. The first refers to a restriction in the possibility of choosing substitutes in the market and the second is associated with the cost of losing continuity. The commitment to continuity is not a decision of the employee, but rather a condition that is given by the environment itself, specifically by the competitive nature of the organization. Competitiveness seen from an internal approach of the organization refers to the changes that companies make to attract consumers, in this case it would be the process of recruitment and selection of personnel, these processes may be associated with the benefits provided by the organization to its employees such as health insurance and scholarships among others depending on each company, benefits that when trying to change organization the employee would not find or it would be difficult to find them, in any case it would involve a risk for the same worker.

\section{Regulatory Commitment}

Normative commitment for Böhrt and Larrea (2018) implies remaining in an organization for a moral duty of reciprocity, i.e. it is based on the attachment that the collaborator has with the organization that employs him/her, in the feeling of loyalty which is expressed through feelings of obligation to endure in the organization to fulfill a duty. It is related to imperative feelings of permanence due to personal norms and values that indicate that loyalty is desirable and that all employees should be loyal to the organization that employs them, thus serving if necessary or possible. It also responds to the moral gratitude of permanence which arises from having received some benefit, opportunity, concession, or special advantage from the organization. The normative commitment has a feeling based on the duty or obligation to remain in the organization. This component is related to the ethics and morale of internal customers, which goes through a process of socialization in the organization, which generates feelings of retribution towards the organization where he works, turning it into obligation and 
loyalty to the rules, policies, values, mission, vision and organizational objectives. According to the above, this last component generates in the collaborator feelings of retribution that translate into the duty to continue belonging to the company (Betanzos \& Rodríguez, 2007).

\subsubsection{Benefits of organizational commitment}

The benefits of organizational commitment can be established as the development of an employee within an organization, among the most relevant are the increase in productivity, effectiveness and efficiency of each employee, the improvement of the work environment within the company, the promotion of teamwork, the improvement of the company's profitability, a speed in the resolution of conflicts and finally the employees feel more involved in achieving the company's goals and finally the rates such as absenteeism in the organization and tardiness are also reduced with the proper management of organizational commitment.

\section{Research model and hypotheses}

For the Internal Marketing variable, the following conceptual constructs and their respective items were considered:

a) Staff development (PD): I receive training according to my skills (PD1), I receive training on various work-related topics (PD2) and training hours are sufficient (PD3).

b) Recruitment of personnel (CC): There is adequate management of the personnel recruitment process (CC1), I had good experience in the recruitment and selection process $(\mathrm{CC} 2)$ and I received the necessary information about the job profile and its functions (CC3).

c) Adequacy to work (AT): The space available to me is adequate for my activities (AT1), the work area is pleasant (AT2) and my immediate supervisor allows me to perform my duties well (AT3).

d) Internal communication (IC): My supervisor informs me about important company issues and changes (IC1), the company disseminates cultural and integration activities in a timely manner (IC2) and I am given the opportunity to communicate my needs and contribute ideas (IC3).

For the Organizational Commitment variable, the following conceptual constructs and their respective items were considered:

a) Affective commitment (AC): I consider myself an important part of the company (AC1), the organization has a very great personal meaning (AC2) and I would be very happy to dedicate the rest of my career to the organization (AC3).

b) Commitment to stay (CP): It motivates me to know that I can grow professionally within the company (CP1), if I decided to leave the organization now, my life would be quite unstructured (CP2), in the current situation staying in the organization is more of a necessity than a desire (CP3) and it would be easy for me to get another job (CP4).

c) Normative commitment (NC): I comment positively about the company with my family and friends (NC1), I see myself working in this company in the long term (NC2), I feel that my work in the organization is valued (NC3), the organization provides me with the necessary benefits to satisfy my needs (NC4) and the organization deserves my loyalty (NC5).

From which the following conceptual model and hypotheses are established.

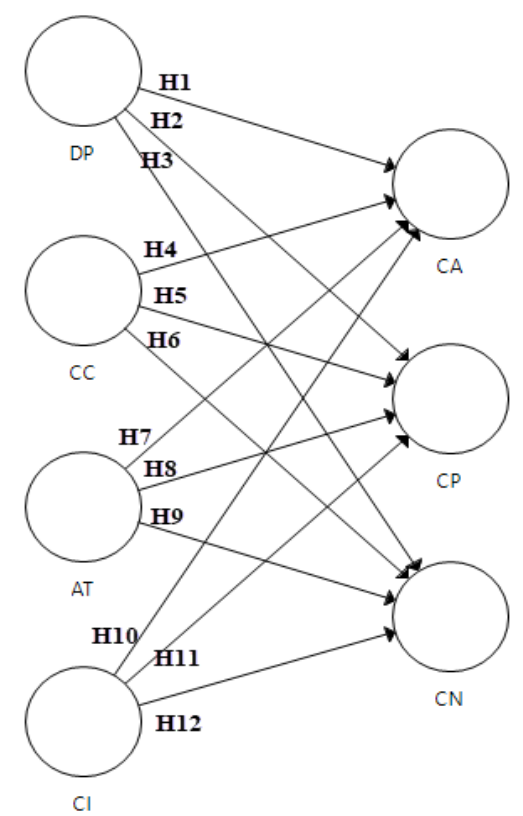

Fig. 1. Conceptual model and hypotheses 
$\mathbf{H}_{1}$ : Staff development positively influences affective organizational commitment.

$\mathbf{H}_{2}$ : Staff development positively influences the commitment to organizational permanence.

H3: Staff development positively influences organizational normative commitment.

$\mathbf{H}_{4}$ : Staff recruitment positively influences affective organizational commitment.

H5: The hiring of personnel positively influences the commitment to organizational permanence.

$\mathbf{H}_{6}$ : Staff recruitment positively influences organizational normative commitment.

H7: Job fit positively influences affective organizational commitment.

$\mathbf{H}_{8}$ : Job fit positively influences the commitment to organizational permanence.

H9: Job fit positively influences organizational normative commitment.

H10: Internal communication positively influences affective organizational commitment.

$\mathbf{H}_{11}$ : Internal communication positively influences the commitment to organizational permanence.

$\mathbf{H}_{12}$ : Internal communication positively influences organizational normative commitment.

\section{Method}

A quantitative correlational study was conducted with a non-experimental design, from March 2021 to July 2021.

\subsection{Population and sample}

For the present research, the study population consisted of employees of companies in the retail sector, made up of men and women, between the age ranges of 18 to 55 years and older, who are employees belonging to the retail sector, in the department of Junín had an increase of 4.7\% between 2017 and 2018, going from 86,327 companies to 90424 (Instituto Nacional de Estadística e Información [INEI], Estructura Empresarial 2018) with a margin of error of 5\%.

\subsection{Data collection instrument}

For data collection, a questionnaire was developed consisting of 37 determinant questions with Likert scale response type in a range of 5 points for the evolution of the questions (the first not observed and the last always), for internal marketing it consisted of four dimensions ( 5 questions for personal development, 5 for recruitment and retention of employees, 6 for job suitability and 6 for internal communication), for organizational commitment it consisted of 3 dimensions ( 5 for affective commitment, 5 for commitment to permanence and finally 5 for normative commitment). For the validation of the instrument, the Delphi methodology was considered and validated by 2 experts. The reliability of the instrument had a high coefficient according to the parameters of cronbach's alpha, exceeding .700 in all dimensions.

\section{Results}

\subsection{Assessment of the Measurement Model}

Table 1 shows the measurement analysis of the model, based on the reliability and validity of the measurement scales. With respect to reliability, the internal consistency of the scales is evidenced through the Cronbach Alpha value (between 0.714 to 0.881 ) and the composite reliability (between 0.840 to 0.914 ). With respect to convergent validity, all factor loadings are above 0.799. Likewise, all scales have average variance extracted (AVE) percentages greater than $60 \%$. The discriminant validity of the construct was tested by the Fornell Larcker criteria, which verifies the independence of each of the scales, considering that the square root of the AVE is greater than the correlations with the rest of the scales. In all cases, the assumption was met.

Table 1

Results of the model measurement analysis

\begin{tabular}{cccccc}
\hline Variables & $\begin{array}{c}\text { Cronbach } \\
\text { alpha }\end{array}$ & $\begin{array}{c}\text { Composite } \\
\text { reliability }\end{array}$ & $\begin{array}{c}\text { Factor loads } \\
\text { (range) }\end{array}$ & $\begin{array}{c}\text { Average variance } \\
\text { extracted (AVE) }\end{array}$ & $\begin{array}{c}\text { Discriminant } \\
\text { Validity }\end{array}$ \\
\hline DP & 0.834 & 0.889 & $0.808-0.835$ & 0.667 & 0.817 \\
CC & 0.791 & 0.865 & $0.739-0.861$ & 0.618 & 0.786 \\
AT & 0.811 & 0.875 & $0.780-0.820$ & 0.637 & 0.798 \\
CI & 0.823 & 0.883 & $0.768-0.852$ & 0.653 & 0.808 \\
CA & 0.714 & 0.840 & $0.742-0.877$ & 0.638 & 0.799 \\
CP & 0.881 & 0.914 & $0.721-0.903$ & 0.681 & 0.825 \\
CN & 0.855 & 0.897 & $0.677-0.898$ & 0.638 & 0.799 \\
\hline
\end{tabular}


As shown in Fig. 2, in all cases an $\mathrm{R}^{2}$ greater than 0.66 was obtained, which is highly significant, showing that the model significantly explains the variance of the conceptual constructs of the dependent variable.

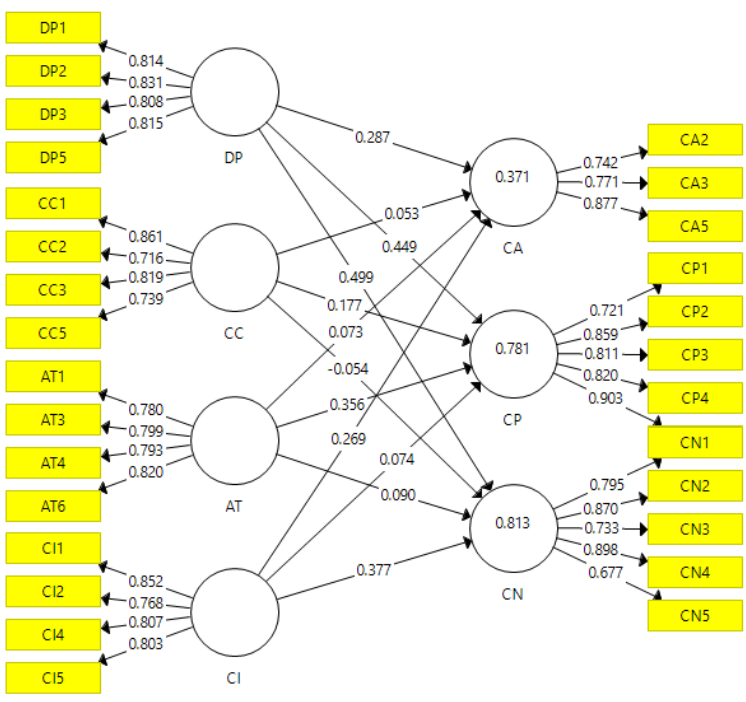

Fig. 2. Results for the hypothesized model with structural equations

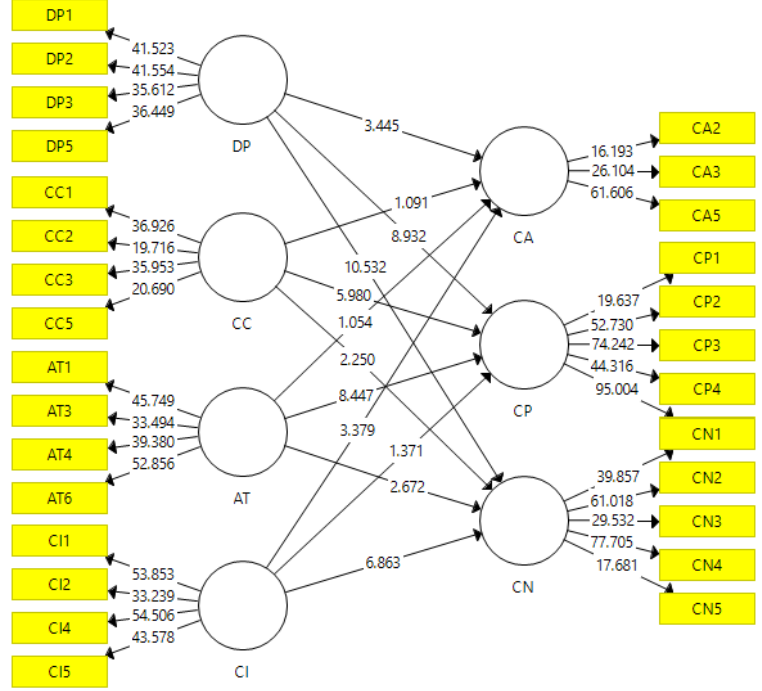

Fig. 3. Modeling Relationship Marketing in Organizational Commitment

\subsection{Assessment of the Structural Model}

After verifying the validity and reliability of the measurement model, the relationships of the constructs were tested. Hypotheses were tested by examining the road coefficients and their significance levels. Bootstrapping was performed with 5500 subsamples to verify the statistical significance of each of the road coefficients (Oré-Calixto \& Vicente-Ramos, 2021). Fig. 3 shows the estimated path of the PLS analysis. Considering that the 3 specific relationships have $\mathrm{p}<0.05$, all the proposed hypotheses are accepted as shown in Table 2.

Table 2

Results of the model structure analysis

\begin{tabular}{cccccc}
\hline Hypotheses & Mean sample & $\begin{array}{c}\text { Standard } \\
\text { deviation }\end{array}$ & Beta & p value & Decision \\
\hline $\mathrm{DP} \rightarrow \mathrm{CA}$ & 0.290 & 0.083 & 3.445 & 0.001 & Accept H1 \\
$\mathrm{DP} \rightarrow \mathrm{CP}$ & 0.449 & 0.05 & 8.932 & 0.000 & Accept H2 \\
$\mathrm{DP} \rightarrow \mathrm{CN}$ & 0.500 & 0.047 & 10.532 & 0.000 & Accept H3 \\
$\mathrm{DC} \rightarrow \mathrm{AC}$ & 0.053 & 0.048 & 1.091 & 0.276 & Denies H4 \\
$\mathrm{CC} \rightarrow \mathrm{CP}$ & 0.176 & 0.03 & 5.98 & 0.000 & Accept H5 \\
$\mathrm{CC} \rightarrow \mathrm{CN}$ & -0.052 & 0.024 & 2.25 & 0.025 & Accept H6 \\
$\mathrm{AT} \rightarrow \mathrm{CA}$ & 0.075 & 0.069 & 1.054 & 0.292 & Denies H7 \\
$\mathrm{AT} \rightarrow \mathrm{CP}$ & 0.355 & 0.042 & 8.447 & 0.000 & Accept H8 \\
$\mathrm{AT} \rightarrow \mathrm{CN}$ & 0.088 & 0.034 & 2.672 & 0.008 & Accept H9 \\
$\mathrm{CI} \rightarrow \mathrm{CA}$ & 0.267 & 0.08 & 3.379 & 0.001 & Accept H10 \\
$\mathrm{CI} \rightarrow \mathrm{CP}$ & 0.075 & 0.054 & 1.371 & 0.170 & Denies H11 \\
$\mathrm{CI} \rightarrow \mathrm{CN}$ & 0.378 & 0.055 & 6.863 & 0.000 & Accept H12 \\
\hline
\end{tabular}

\section{Discussion and conclusion}

\section{Regarding the impact of Internal Marketing on Affective Organizational Engagement}

A high influence between internal marketing and affective organizational commitment has been obtained as a result (0.714) according to Cronbach's alpha and a significant influence on the internal marketing criteria $(\mathrm{p}<0.05)$, therefore H1 is accepted, and a high correlation between the two variables is reaffirmed. This coincides with Salvador and Hernández (2006) who indicate that affective commitment is one of the three most studied types of commitment, which refers to the emotional ties that employees develop towards an organization, and which leads them to feel proud of being members of an organization. Meyer and Allen (1991) point out that people who have a high affective component are willing to make additional efforts in their performance, since a link to the organization arises from feeling fairly treated in their work environment, and at the same 
time these are expressed through identification with the company's objectives and values, a greater effort to achieve the proposed goals and objectives, as well as the desire and satisfaction of belonging to the organization. The CA is the ability of a collaborator to feel emotionally secure within the organization when thinking that the organization cares and is responsible for their expectations, it is also worth noting the influence of affective commitment on the emotional intelligence of the collaborator because if this is not applied correctly it would only cause a negative influence on the person causing problems in the organization and in the organizational climate, the culture of the same one and even in the achievement of results since it is necessary to bear in mind that the human being is a being made and motivated by emotions and that these emotions are the most representative of every sociable being.

\section{Regarding the impact of Internal Marketing on Organizational Retention Commitment}

As a result, a high influence between internal marketing and organizational permanence commitment was obtained (0.881) according to Cronbach's alpha and a significant influence on the internal marketing criteria $(\mathrm{p}<0.05)$, therefore $\mathrm{H} 1$ is accepted, and a high correlation between the two variables is reaffirmed. According to Arias (2001), the dimension of continuous commitment is based on the costs, such as financial costs, benefits obtained, among others, which an employee may lose when leaving an organization, so that leaving the company would imply a high cost for the person, due to the low probability of finding another job with the same benefits. Meyer and Allen (1997) gives a focus to the financial benefits and costs that a worker would lose when leaving an organization, some of the most prominent phrases found in the CC are "I continue working because outside the company it would be difficult for me to get a job like the one I have", "I could not have the same quality of life if I left this job", among many others, all based on the satisfaction of needs that can help to supply the organization. Finally, taking into account that the pandemic caused in the year 2020 has caused an increase in the unemployment rate, a greater efficiency by employees to keep their jobs, salary cuts among many others, we can see that assessing the commitment of continuity for an organization is very important because an employee who only works for fear of losing organizational benefits does not produce or perform as well as an employee who works because he feels morally identified with his own organization.

\section{Regarding the impact of Internal Marketing on Organizational Normative Commitment}

As a result, a high influence between internal marketing and organizational permanence commitment was obtained (0.855) according to Cronbach's alpha and a significant influence on the internal marketing criteria $(\mathrm{p}<0.05)$; therefore, H1 is accepted and a high correlation between the two variables is reaffirmed. Related to Betanzo and Rodriguez (2007) who argue that normative commitment is the least studied of the three types of commitment already seen and also determines that the manifestation of normative commitment implies remaining in the organization to fulfill a moral duty of reciprocity, i.e. out of gratitude. Böhrt and Larrea (2018) indicate that this type of commitment is based on the degree of attachment of the collaborator to the organization, in reference to a sense of loyalty and is expressed in feelings of obligation to remain in the organization for the fulfillment of a duty, it is related to the feelings of continuing in the organization because the established values and norms suggest that all collaborators must be faithful and loyal to the employer company and serve efficiently as long as possible. The commitment to continuity also responds to the moral mandate to remain in the organization and this may have arisen when the employee has perceived advantage, opportunity or special benefit in the organization. Betanzo and Rodriguez (2007) also name it as a commitment of moral obligation, and a relevant aspect of the normative commitment is also detailed, which is associated with the so-called organizational citizenship behaviors, which are expressed in different types of pro-social behavior, those that being voluntary are not supported by the system of responsibilities, compensation, and benefits that a job position provides. Basically it can be determined that although it is true that this type of commitment lacks more studies, this can be rooted in the psychosocial bases that every individual has when receiving help, taking into account that the morality and the regimentation of an individual within a society are basic aspects of every person, so we could ensure that the normative commitment of a person to the organization will be determined by the degree of the need that this has to be employed within the same and how the organization recruits and selects the candidate.

\section{References}

Albinez Loayza, S., \& Gallardo Montoya, M. (2020). Level of organizational commitment according to sociodemographic variables in a private company in Callao. Lima: Universidad Cesar Vallejo.

Arango, A. M. A. (2016). Continuity commitment and the consumer's bond with the organization. Cuadernos de Administración, 29(53), 181-201.

Arias, F. (2001). The personal commitment to the organization and the intention of permanence: some factors for its increase. Journal of Accounting and Administration, 200(200) 5-12

Betanzos Diaz, N., \& Paz Rodriguez, F. (2007). Psychometric Analysis on Organizational Commitment as attitudinal variable. Anales de Psicología, 23(2), 207-215.

Bohnenberger, M. C. (2006). Marketing interno: la actuación conjunta entre recursos humanos y marketing en busca del compromiso organizacional. Universitat de les Illes Balears.

Böhrt, R. \& Larrea, P. (2018). Relación entre compromiso normativo y apoyo organizacional percibido en empleados de oficina. Ajayu Órgano de Difusión Científica del Departamento de Psicología UCBSP, 16(2), 220-251. 
Broady-Preston, J., \& Steel, L. (2002), Employees, customers and internal marketing strategies in LIS, Library Management, 23(8/9), 384-393.

Chiavenato, I. (2006). Introducción a la teoría general de la Administración (17th ed.). Mexico City, Mexico: Mc Graw-Hill.

Deming, E. (1989). Quality Productivity and Competitive Position. Cambridge: Cambridge University Press.

Edel, R., García Santillán, A., \& Bustamante, R. (2007). Clima y compromiso organizacional. Biblioteca virtual de Derecho, Economía y Ciencias Sociales, México.

Guaderrama, A. I. M. (2016). Culture and affective commitment: do they influence internal knowledge transfer? Contaduría y Administración, 61(4), 666-681.

Hernández Bonilla, B. E., Ruiz Reynoso, A. M., Ramírez Cortés, V., Sandoval Trujillo, S. J., \& Méndez Guevara, L. C. (2018). Motivos y factores que intervienen en el compromiso organizacional / Reasons and factors involved in the organizational commitment. RIDE Revista Iberoamericana para la investigación y el desarrollo educativo, 8(16), 820 846).

Hewitt, A. (2017). Tendencias globales de compromiso de empleados 2017.

Lings, I. N. (2004). Internal market orientation: Construct and consequences. Journal of business research, 57(4), $405-413$.

Meyer, J. P., \& Allen, N. J. (1991). A three-component conceptualization of organizational commitment. Human Resource Management Review, 1(1), 61-89.

Meyer, J. P., \& Allen, N. J. (1997). Commitment in the workplace: Theory, research, and application. Sage publications.

Hunt, S.D. \& Morgan, R. (1995). The Comparative Advantage Theory of Competition. Journal of Marketing, 59(2), 1-15.

Oré-Calixto, S., \& Vicente-Ramos, W. (2021). The effect of digital marketing on customer relationship management in the education sector: Peruvian case. Uncertain Supply Chain Management, 9(3), 549-554.

Ospina, M. P. (May 15, 2019). Endomarketing the heart of the brand. Human Capital.

Rafiq, M., \& Ahmed, P. K. (2000). Advances in the internal marketing concept: definition, synthesis and extension. Journal of Services Marketing, 14(6), 449-462.

Rafiq, M. \& Ahmed, P. (1993). The scope of internal marketing: defining the boundary between marketing and human resource management. Journal of Marketing Management, 9(3), 219-232.

Salvador, C., \& Hernández, R. (2006). Participation and commitment in the quality of Paraguayan services. Interamerican Journal of Psychology, 40(3), 363-370.

Slocum, J. W., \& Hellriegel, D. (2009). Principles of organizational behavior. Mason, OH: South-Western Cengage Learning.

Uribe Prado, J. F., Patlán Pérez, J., \& García Saisó, A. (2015). Psychosomatic manifestations, commitment and burnout as cosequents from climate and organization culture: a path analysis. Contaduría y Administración, 60(2), 447-467.

Zegarra Del Rosario, F.E. (2014) Relación entre marketing interno y compromiso organizacional en el personal de salud del Hospital de San Juan Lurigancho. Universidad Nacional Mayor de San Marcos, Lima, Perú. 
(C) 2021 by the authors; licensee Growing Science, Canada. This is an open access article distributed under the terms and conditions of the Creative Commons Attribution (CCBY) license (http://creativecommons.org/licenses/by/4.0/). 